\title{
Drivers of Industrial and Non-Industrial Greenhouse Gas Emissions
}

\section{CCEP Working Paper 1502 March 2015}

\author{
Luis F. Sanchez \\ Crawford School of Public Policy, The Australian National University \\ David I. Stern \\ Crawford School of Public Policy, The Australian National University
}

\begin{abstract}
There has been extensive analysis of the drivers of carbon dioxide emissions from fossil fuel combustion and cement production, which constituted only $55 \%$ of global greenhouse gas (GHG) emissions in 1970 and $65 \%$ in 2010 . But there has been much less analysis of the drivers of greenhouse gases in general and especially of emissions of greenhouse gases from agriculture, forestry, and other land uses, which we call non-industrial emissions in this paper, that constituted $24 \%$ of total emissions in 2010 . We statistically analyse the relationship between both industrial and non-industrial greenhouse gas emissions and economic growth and other potential drivers for 129 countries over the period from 1971 to 2010 . Our analysis combines the three main approaches in the literature to investigating the evolution of emissions and income. We find that economic growth is a driver of both industrial and non-industrial emissions, though growth has twice the effect on industrial emissions. Both sources of emissions decline over time though this effect is larger for non-industrial emissions. There is also convergence in emissions intensity for both types of emissions but given these other effects there is no evidence for an environmental Kuznets curve.
\end{abstract}




\section{Keywords:}

Greenhouse gas emissions; economic growth; decoupling; pollution; environmental Kuznets curve, convergence

JEL Classification:

Q54, Q56

\section{Suggested Citation:}

Sanchez, L.F. and Stern, D.I. (2015), Drivers of Industrial and Non-Industrial Greenhouse Gas Emissions, CCEP Working Paper 1502, March 2015. Crawford School of Public Policy, The Australian National University.

\section{Address for Correspondence:}

David I. Stern

Professor

Crawford School of Public Policy

The Australian National University

132 Lennox Crossing

Acton

ACT 2601

Australia

Tel: +61261250176

Email: david.stern@anu.edu.au

The Crawford School of Public Policy is the Australian National University's public policy school, serving and influencing Australia, Asia and the Pacific through advanced policy research, graduate and executive education, and policy impact.

The Centre for Climate Economics \& Policy is an organized research unit at the Crawford School of Public Policy, The Australian National University. The working paper series is intended to facilitate academic and policy discussion, and the views expressed in working papers are those of the authors. Contact for the Centre: Dr Frank Jotzo, frank.jotzo@anu.edu.au 


\title{
Drivers of Industrial and Non-Industrial Greenhouse Gas Emissions
}

\author{
Luis F. Sanchez
}

Crawford School of Public Policy, The Australian National University, 132 Lennox Crossing, Acton, ACT 2601, Australia. luis.sanchez@anu.edu.au

David I. Stern*

Crawford School of Public Policy, The Australian National University, 132 Lennox Crossing, Acton, ACT 2601, Australia.david.stern@anu.edu.au

27 March 2015

\begin{abstract}
There has been extensive analysis of the drivers of carbon dioxide emissions from fossil fuel combustion and cement production, which constituted only $55 \%$ of global greenhouse gas (GHG) emissions in 1970 and 65\% in 2010. But there has been much less analysis of the drivers of greenhouse gases in general and especially of emissions of greenhouse gases from agriculture, forestry, and other land uses, which we call non-industrial emissions in this paper, that constituted $24 \%$ of total emissions in 2010 . We statistically analyse the relationship between both industrial and non-industrial greenhouse gas emissions and economic growth and other potential drivers for 129 countries over the period from 1971 to 2010. Our analysis combines the three main approaches in the literature to investigating the evolution of emissions and income. We find that economic growth is a driver of both industrial and non-industrial emissions, though growth has twice the effect on industrial emissions. Both sources of emissions decline over time though this effect is larger for nonindustrial emissions. There is also convergence in emissions intensity for both types of emissions but given these other effects there is no evidence for an environmental Kuznets curve.
\end{abstract}

Key Words: Greenhouse gas emissions, economic growth, decoupling, pollution, environmental Kuznets curve, convergence.

* Corresponding author

Acknowledgements: We thank Paul Burke, Reyer Gerlagh, and Muhammad Shahiduzzaman for useful comments. 


\section{Introduction}

There has been extensive analysis of the drivers of carbon dioxide emissions from fossil fuel combustion and cement production (e.g. Raupach et al., 2007; Jotzo et al., 2012; Steinberger et al., 2012; Jorgenson, 2014, Blanco et al., 2014), which constituted only 55\% of global greenhouse gas (GHG) emissions weighted by global warming potential in 1970 and $65 \%$ in 2010 (IPCC, 2014). But there has been much less analysis of the drivers of greenhouse gases in general and especially of emissions of greenhouse gases from agriculture, forestry, and other land uses constituting $24 \%$ of total emissions in 2010, which we call non-industrial emissions in this paper. We statistically analyse the relationship between both industrial and non-industrial greenhouse gas emissions and economic growth and other potential drivers for 129 countries over the period from 1971 to 2010. We find that economic growth is a driver of both industrial and non-industrial emissions, though growth has twice the effect on industrial emissions. Both sources of emissions are declining over time in the absence of economic growth with this effect larger for non-industrial emissions.

Figure 1 shows that there is a positive correlation between the long-run average growth rate of per capita GHG emissions and the long-run growth rate of gross domestic product (GDP) per capita. Fast-growing economies typically see increases in GHG emissions while slowgrowing or declining economies tend to have declining emissions. The remaining variation around this main relationship reflects differences in the rate of change in emissions per dollar of GDP or emissions intensity. The 45-degree line in each panel of the Figure indicates the locus of zero change in emissions intensity. Emissions intensity was declining in the majority of countries. Some fast-growing economies such as China - the large circle to the right in each panel - saw significant declines in emissions intensity, in many cases at a faster rate than in most developed countries. It is also apparent that there is a stronger relationship between industrial emissions growth and economic growth than between non-industrial emissions growth and economic growth.

Three main approaches have dominated the literature on the drivers of pollution emissions and other environmental impacts (Anjum et al., 2014; Blanco et al., 2014). The analysis in this paper allows us to test all three in a single equation framework. The first approach is the IPAT model proposed by Ehrlich and Holdren (1971) and the related Kaya Identity and derived structural decomposition approaches (e.g. Raupach et al., 2007). IPAT is an identity 
a.

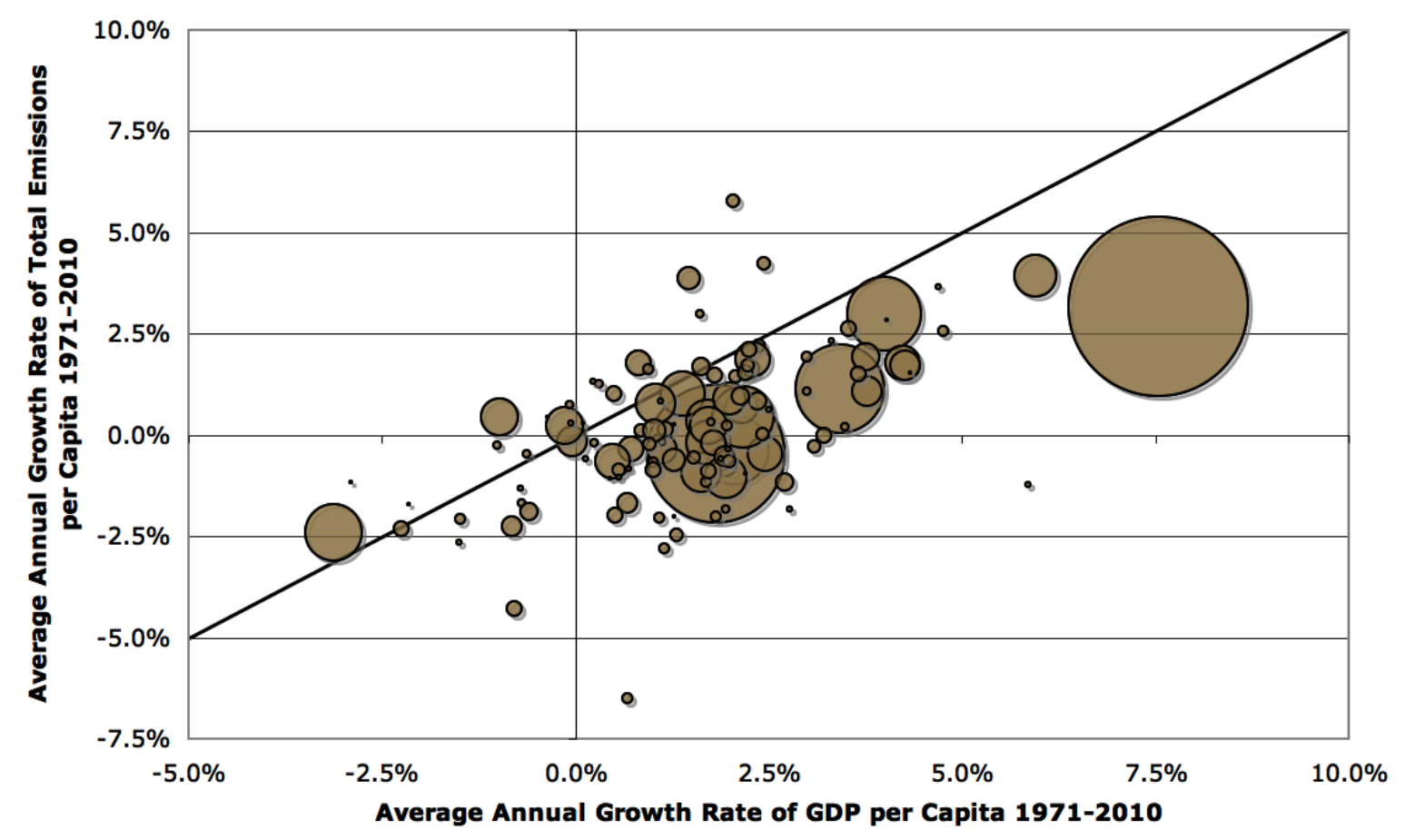

b.

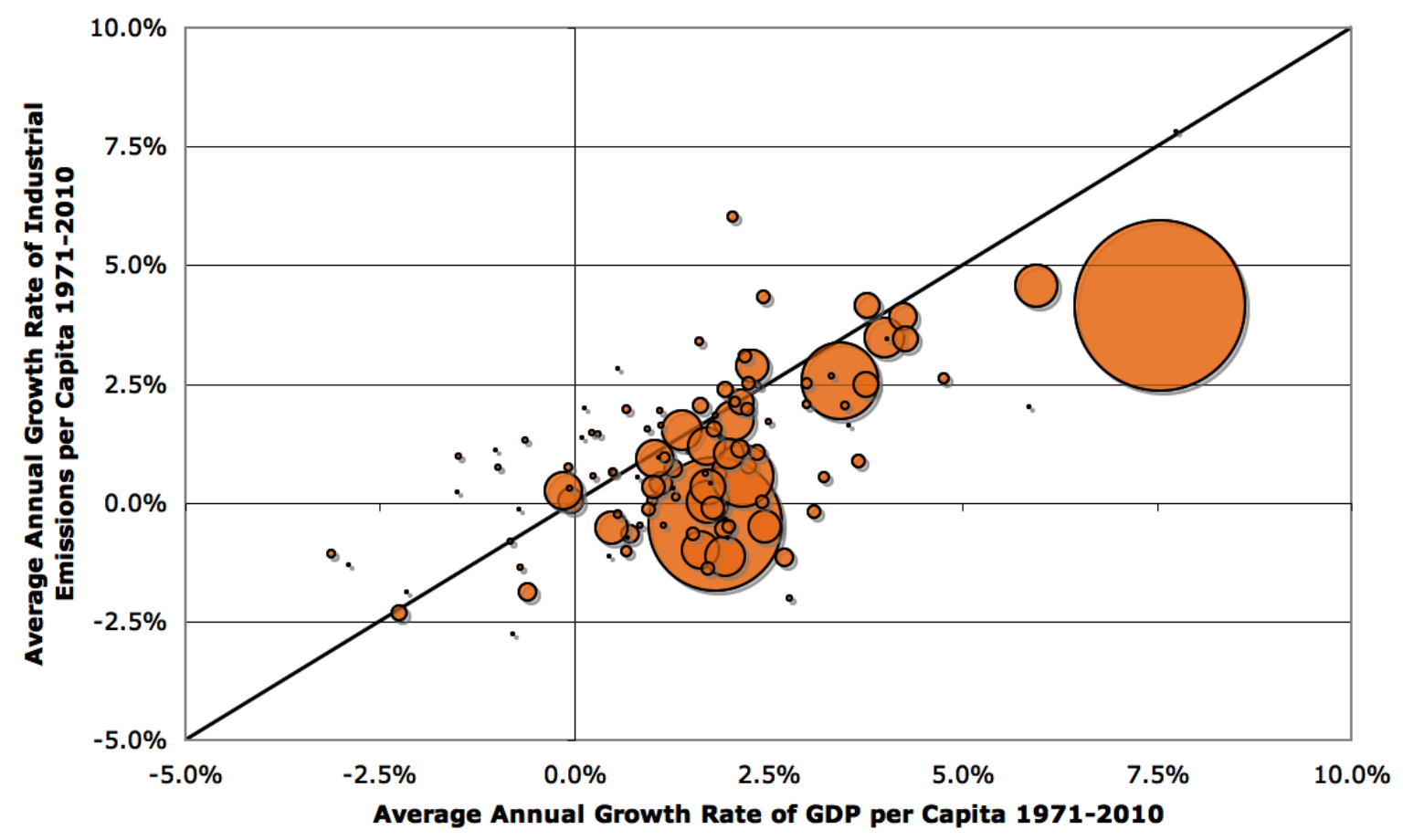


c.

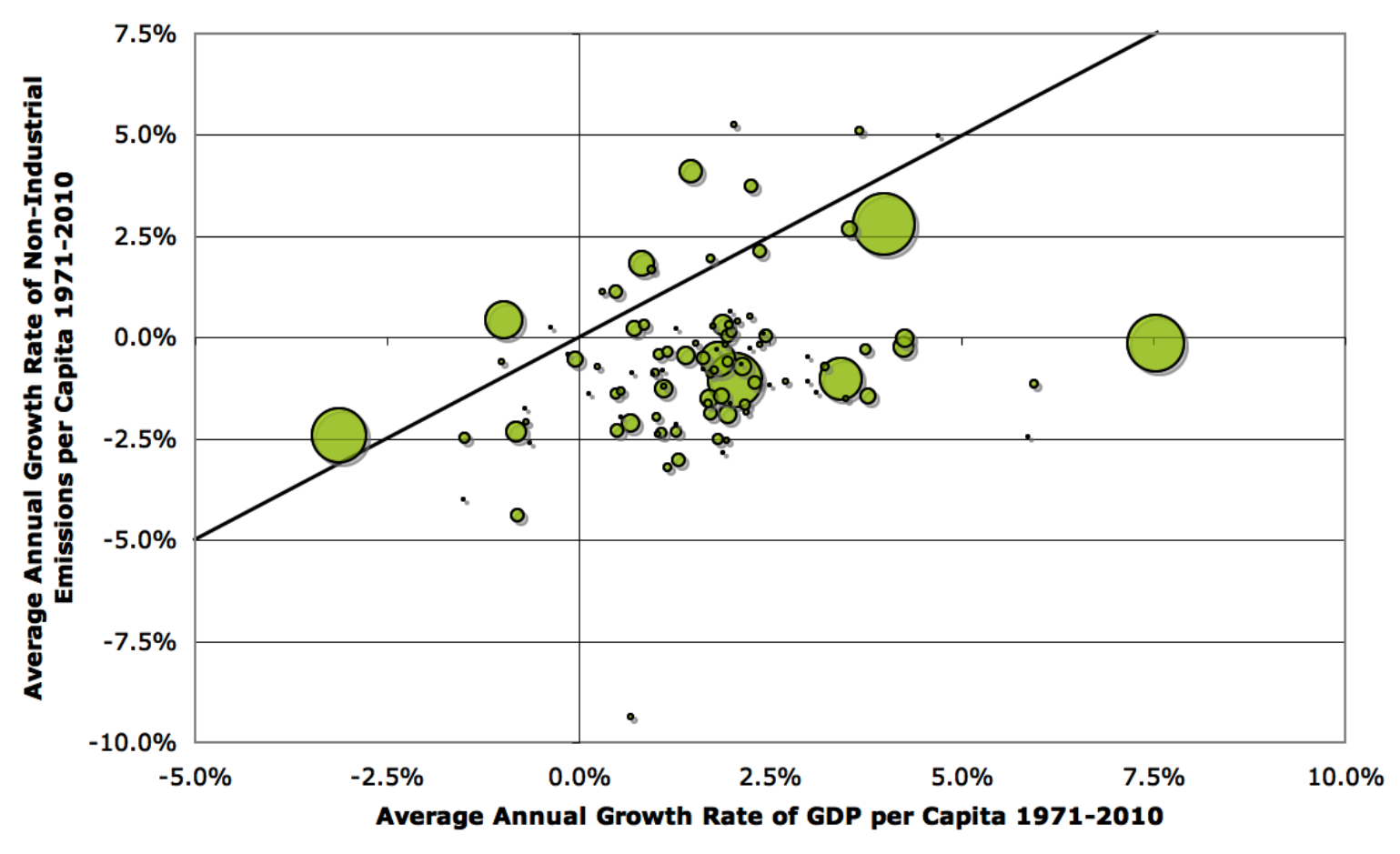

Figure 1: Growth Rates of Per Capita Income and Per Capita Greenhouse Gas

Emissions: a. Total Emissions. b. Industrial Emissions. c. Non-Industrial Emissions. The figure shows the relation between the average annual growth rates of per capita income and per capita emissions from non-industrial sources from 1971 to 2010. The size of the circles is proportional to countries' total emissions from the respective sources in 2010 and are scaled in panels b. and c. so that they the magnitudes are comparable to the quantities in panel a. Points along the 45-degree lines have constant emissions intensity.

given by impact $\equiv$ population $\times$ affluence $\times$ technology. If affluence is taken to be income per capita, then the technology term is impact or emissions per dollar of income. ${ }^{1}$

The second main approach to modelling the income-emissions relationship - the environmental Kuznets curve (EKC) - proposes that environmental impacts first increase and then decrease over the course of economic development. Most research, however has found that carbon dioxide emissions do not follow such a pattern and other research has challenged the existence of such a relationship for emissions of other pollutants too (Stern, 2004; Carson, 2010; Pasten and Figueroa, 2012; Kaika and Zervas, 2013a, 2013b).

${ }^{1}$ STIRPAT is another popular modelling approach, which uses the basic logic of IPAT, but allows for the effects of right-hand side variables to be empirically estimated rather than assumed to have a unit elasticity (York et al., 2003) and implicitly considers the relationship to be causal rather than an identity. 
The third main approach to the evolution of emissions over time is to hypothesize that they are converging to a common level with emissions growing more slowly in emissions intensive countries than in less emissions intensive countries. Existing evidence is mixed and seems to depend on the methods used (Petterson et al., 2014). Sigma and stochastic convergence methods tend to find convergence only among the developed economies (e.g. Strazicich and List, 2003; Westerlund and Basher, 2008) or club convergence (Herrerias, 2013). On the other hand, the beta convergence method is more likely to find global convergence (e.g. Brock and Taylor, 2010; Brännlund et al., 2014).

In this paper, we find that there is a significant effect of economic growth on long-run growth in both industrial and non-industrial emissions, although we find no support for the EKC hypothesis for either type of emissions. Instead, time and convergence effects and the effects of some specific control variables are significant. On the other hand, there is a reduction in emissions intensity with growth, particularly for non-industrial emissions. This rules out a simple IPAT style model too.

\section{Methods}

Our model combines the three main approaches in the literature and includes other possible drivers of emissions growth by nesting these existing specifications in a single regression equation. We estimate the following regression model for each of total, industrial, and nonindustrial emissions:

$$
\hat{E}_{i}=\alpha+\beta_{1} \hat{G}_{i}+\beta_{2} G_{i} \hat{G}_{i}+\gamma G_{i}+\delta\left(E_{i 0}-G_{i 0}\right)+\sum_{j} \psi_{j} X_{j i}+\varepsilon_{i}
$$

where $i$ indexes countries and $\varepsilon_{i}$ is a random error term. $\hat{E}_{i}$ is the long-run growth rate of per capita emission and $\hat{G}_{i}$ of income per capita. $G_{i}$ is the log of income per capita averaged over time in each country and $E_{i 0}-G_{i 0}$ is the $\log$ of emissions intensity in $1971 . X$ is a vector of additional explanatory or "control" variables listed in Table 2. The first term on the RHS of the equation is the average time effect - the rate of change in emissions when there is no economic growth and all the other variables are at their sample means. The second is the effect of economic growth at the sample mean and the third - the interaction term - tests for the EKC effect. If its coefficient is statistically significantly negative, then there is a level of income after which emissions start to reduce with growth. The fourth term tests whether 
emissions change at a different rate in richer countries in the absence of growth and the fifth term is intended to model convergence. If its coefficient is negative, then emissions grow more slowly in emissions intensive countries and vice versa.

Long-run growth rates are computed using: $\hat{X}_{i}=\left(X_{i T}-X_{i 0}\right) / T$, where, $X$ is the logarithm of per capita emissions or income, $T$ is the final year of the time series in levels, 0 indicates the initial year, and $i$ indexes countries. By formulating our model in long-term growth rates we avoid most of the econometric problems troubling the existing literature, which are discussed in several recent contributions to the literature on the environmental Kuznets curve (Wagner, 2008, in press; Vollebergh et al., 2009; Stern, 2010; Anjum et al., 2014).

We subtract the means of all variables apart from $\hat{E}_{i}$ and the dummy variable for non-English legal origin prior to estimation. $\alpha$ is, therefore, an estimate of the mean of $\hat{E}_{i}$ for countries with zero economic growth and average values of all the other variables and thus is equivalent to the time effect in traditional EKC models in levels. $\beta$ is an estimate of the income-emissions elasticity at the sample mean. We can find the EKC turning point, $\mu$, by estimating the regression without demeaning log income and computing $\mu=\exp \left(-\beta_{1} / \beta_{2}\right)$.

Including the initial level of emissions intensity per dollar of GDP, allows us to test for convergence in emissions intensity using the beta convergence approach (Barro and Sala-iMartin, 1992; Brock and Taylor, 2010). If $\delta<0$, then emissions intensity converges across countries so that emissions growth is slower in countries that commence the period with higher emissions intensity and vice versa.

A wide variety of "control variables" have been considered in the EKC literature. Some of these are genuinely exogenous or predetermined, whereas others are variables that typically change in the course of economic development and might be seen as factors through which the development process drives emissions changes. Examples of the latter are democracy, free press, good governance, and lack of corruption, or industrial structure, all of which are clearly driven by income growth or develop alongside GDP as part of the development process. We are interested in testing the overall effect of income and economic growth on emissions growth and so our main analysis only includes variables that are pre-determined or exogenous to the development process and found in previous research to be potentially relevant (Anjum et al., 2014). 
Stern (2005) first noted that English speaking OECD countries seemed to abate sulphur emissions less and Germanic and Scandinavian countries more. Stern (2012) related this to differences in legal origins (La Porta et al., 2008) and found that energy intensity was lower in non-English legal origin countries, ceteris paribus. Here, we include a dummy for nonEnglish legal origin. Brännlund et al. (2014) find that institutional quality has a negative direct effect on growth in per capita emissions but has a positive effect on economic growth and, therefore, a net positive effect on emissions growth. Due to the high growth rates in China and South Korea, German legal origin countries grow significantly faster than English legal origin countries in our sample. The effect we measure though is the effect of legal origin controlling for the rate of economic growth. And even this effect turns out to be positive.

Initially, we also included a dummy for centrally planned economies on the expectation that reform in the formerly centrally planned countries spurred reductions in industrial emissions. But this variable was not statistically significant in any of our regressions and so we dropped it.

We control for the effect of climate, which obviously has important effects on energy use by using historical country averages of temperatures over the three summer months and the three winter months. Because these are climatic averages for 1960-1990 and the emissions of individual countries do not significantly affect their own climate, temperature can be taken as exogenous.

Burke $(2012,2013)$ and Stern (2012) argue that resource endowments are likely to have important effects on emissions and energy use. To account for fossil fuel resources, we include the log of estimated per capita fossil fuel endowments in 1971 (Norman, 2009). We take into account the potential for hydroelectric power by controlling for the log of freshwater resources per capita in 1972. Forest resources might be important for the availability of biomass as an energy source but also as the most important contributor to nonindustrial emissions is land-use change we should control for the initial forest cover. We control for forest resources using the log of forest area per person in 1971. Finally, we include the average of the log of population density, which might be expected to increase the rate of deforestation. Furthermore, higher density should be associated with lower energy use in transport and smaller living- and work- spaces. Also, higher densities should encourage governments to limit toxic emissions more, which may also result in lower associated 
emissions of greenhouse gases (Stern, 2005). However, the effect of density on the growth rate of industrial emissions is less clear and density might have an effect simply because it is correlated with other omitted variables.

When observations on variables are aggregated into regions - here countries - of different sizes it is likely that much of the local variation across individual locations is cancelled out in the larger regions while more idiosyncratic variation remains in smaller regions. This means that the error terms in a regression using such aggregated data are likely to be heteroskedastic with the error variance proportional to the district size (Maddala, 1977; Stern, 1994). As our data consists of per capita measures, the appropriate measure of region size is population. In our sample, populations range from 67,000 in Antigua and Barbuda in 1971 to 1.3 billion in China in 2010. To address this grouping heteroskedasticity we estimate the models using population weighted least squares and heteroskedasticity-robust standard errors. Using weighted least squares (WLS) can result in large efficiency gains over using ordinary least squares (OLS) even when the model for reweighting the data is misspecified. But in case there is misspecification, heteroskedasticity robust standard errors should be used to ensure correct inference (Romano and Wolf, 2014). We measure goodness of fit using Buse's (1973) R-squared, weighting the squared deviations by population.

We assume that the explanatory variables in our regressions are exogenous. Clearly, there can be no reverse causality from growth rates to initial values. There is potentially feedback from the growth rate of emissions, especially of carbon dioxide, to either the growth rate of income or the average level of GDP. This feedback is not actually causal but assuming that emissions are correlated with the growth of energy use and energy use contributes to economic growth then it would appear that emissions cause growth. Omitted variables bias is an important issue as there are many variables that may be correlated with GDP or GDP growth, and which may help explain emissions growth. Our differenced approach should help reduce this bias (Angrist and Pischke, 2010). Finally, measurement error is a significant issue in the estimation of GDP and emissions. Obviously there are significant uncertainties in the emissions data, especially for non-industrial emissions, which are discussed in the Appendix. Measurement error is likely greater for some of the smaller economies. Weighted least squares can, therefore, help reduce the effects of this measurement error.

The usual approach to dealing with reverse causality, omitted variables bias, and measurement error is to use instrumental variables. However, it is hard to find plausible 
instrumental variables in the macro-economic context (Bazzi and Clemens, 2013), especially for long-run growth rates or levels of the variables.

\section{Results}

The Appendix describes the data sources in detail. Table 1 presents descriptive statistics for the growth rates of income and emissions per capita and the level of income per capita. There is a large variation in income levels across countries and the distribution is skewed with a smaller number of large (in total income) wealthy economies and many small (in total income) poor economies. The population weighted mean income growth rate is higher than the global aggregate or the mean of countries due to rapid growth in India and China, in particular.

Total per capita GHG emissions rose very slowly in the average country but the population weighted mean grew much more rapidly due to rapid growth in China, in particular, but grew slower than industrial emissions because emissions grew slowly in India, which had negative growth in non-industrial emissions that significantly offset its growth in industrial emissions. The global aggregate grew at only $0.3 \%$ p.a. because many of the largest economies in terms of total emissions are slower growing developed countries such as the United States. These offset rapid growth in China. The variance of per capita emissions growth rates across countries is similar to that of economic growth rates.

Industrial emissions rose at $0.7 \%$ p.a. in the median country. The population weighted mean grew much more rapidly because China and India, the two most populous countries also have rapid rates of industrial emissions growth of $4.2 \%$ p.a. and $2.6 \%$ p.a., respectively. Again, the global aggregate grew more slowly than the population weighted mean $(0.6 \%$ p.a. vs. $2.1 \%$ p.a.). Non-industrial emissions fell at $0.8 \%$ p.a. in the median country. Indonesian emission grew by $2.8 \%$ p.a. off an already substantial base - Indonesia is the largest circle in Figure 1c - and contributed to raising the growth rates of the global aggregate and the population weighted mean above that of the median country. 
Table 1. Descriptive Statistics

\begin{tabular}{|l|l|l|l|l|l|l|l|}
\hline & \multicolumn{3}{|l|}{ Country } & \multicolumn{2}{|l|}{} & $\begin{array}{l}\text { Global } \\
\text { Aggregate }\end{array}$ & $\begin{array}{l}\text { Population } \\
\text { Weighted } \\
\text { Mean }\end{array}$ \\
\cline { 2 - 7 } & Mean & $\begin{array}{l}\text { Standard } \\
\text { Deviatio } \\
n\end{array}$ & Min & \multicolumn{2}{l|}{ Median } & Max & \\
\hline $\begin{array}{l}\text { G.R. Total } \\
\text { Emissions } \\
\text { per Capita }\end{array}$ & 0.002 & 0.018 & -0.065 & 0.001 & 0.076 & 0.003 & 0.011 \\
\hline $\begin{array}{l}\text { G.R. } \\
\text { Industrial } \\
\text { Emissions } \\
\text { per Capita }\end{array}$ & 0.009 & 0.017 & -0.028 & 0.007 & 0.078 & 0.006 & 0.021 \\
\hline $\begin{array}{l}\text { G.R. Non- } \\
\text { Industrial } \\
\text { Emissions } \\
\text { per Capita }\end{array}$ & -0.007 & 0.019 & -0.094 & -0.008 & 0.053 & -0.005 & -0.006 \\
\hline $\begin{array}{l}\text { G.R. GDP } \\
\text { per Capita }\end{array}$ & 0.016 & 0.018 & -0.031 & 0.017 & 0.077 & 0.025 & 0.036 \\
\hline $\begin{array}{l}\text { GDP per } \\
\text { Capita 1971 }\end{array}$ & $\$ 6,385$ & $\$ 9,873$ & $\$ 389$ & $\$ 2,728$ & $\$ 76,354$ & $\$ 4,502$ & $\$ 4,047$ \\
\hline $\begin{array}{l}\text { GDP per } \\
\text { Capita 2010 }\end{array}$ & $\$ 11,696$ & $\$ 12,090$ & $\$ 253$ & $\$ 7,081$ & $\$ 56,236$ & $\$ 11,981$ & $\$ 13,080$ \\
\hline
\end{tabular}

Note: Growth rates are presented in fractions rather than percentages as that is the way the data are used in our regression analysis. The first five columns present unweighted statistics for our sample when computing the statistics for each country separately first. In the sixth column (global) we first compute the total emissions, GDP, and population for our sample of countries and we then compute the mean annual growth rate and mean per capita level of this global aggregate. In the final column we compute the growth rates using population-weighted regressions of the country-level growth rates on a constant. 
Table 2. Regression Results

\begin{tabular}{|l|l|l|l|}
\hline Data set & $\begin{array}{l}\text { Total } \\
\text { Emissions }\end{array}$ & $\begin{array}{l}\text { Industrial } \\
\text { Emissions }\end{array}$ & $\begin{array}{l}\text { Non-Industrial } \\
\text { Emissions }\end{array}$ \\
\hline Constant & $-0.0170^{* * *}$ & $-0.0096^{* * *}$ & $-0.0154^{* * *}$ \\
& $(0.0019)$ & $(0.0014)$ & $(0.0033)$ \\
\hline$\hat{G}_{i}$ & $0.7832^{* * *}$ & $\begin{array}{l}0.8533^{* * *} \\
(0.0484)\end{array}$ & $\begin{array}{l}0.4540^{* * *} \\
(0.1266)\end{array}$ \\
\hline$G_{i}$ & $\begin{array}{l}-0.0696) \\
(0.0018)\end{array}$ & $\begin{array}{l}-0.0035^{* * *} \\
(0.0011)\end{array}$ & $\begin{array}{l}-0.0029 \\
(0.0023\end{array}$ \\
\hline$G_{i} \hat{G}_{i}$ & $0.1979^{* * *}$ & $0.1275^{* * *}$ & 0.0497 \\
$(0.0592)$ & $(0.0414)$ & $(0.0703)$ \\
\hline$E_{i 0}-G_{i 0}$ & $-0.0080^{* * *}$ & $-0.0121^{* * *}$ & $-0.0060^{* * *}$ \\
& $(0.0017)$ & $(0.0016)$ & $(0.0018)$ \\
\hline Non-English Legal Origin & $0.0058^{* * *}$ & $0.0043^{* * *}$ & 0.0030 \\
& $(0.0016)$ & $(0.0012)$ & $(0.0032)$ \\
\hline Summer Temperature & $0.0007^{* *}$ & $0.0012^{* * *}$ & $-0.0013^{* *}$ \\
& $(0.0003)$ & $(0.0002)$ & $(0.0005)$ \\
\hline Winter Temperature & 0.0001 & -0.0001 & $0.0010^{* *}$ \\
& $(0.0002)$ & $(0.0001)$ & $(0.0004)$ \\
\hline Log Fossil Fuel per Capita 1971 & 0.0004 & $0.0007^{*}$ & 0.0002 \\
& $(0.0004)$ & $(0.0004)$ & $(0.0006)$ \\
\hline Log Freshwater per Capita 1971 & 0.0004 & 0.0013 & -0.0008 \\
& $(0.0011)$ & $(0.0009)$ & $(0.0016)$ \\
\hline Log Forest per Capita 1971 & -0.0004 & $-0.0009^{*}$ & 0.0001 \\
& $(0.0007)$ & $(0.0005)$ & $(0.0011)$ \\
\hline Log Population Density & $-0.0018^{* *}$ & $-0.0009^{*}$ & $-0.0039^{* * *}$ \\
& $(0.0009)$ & $(0.0005)$ & $(0.0013)$ \\
\hline $\bar{R}_{\text {Buse }}^{2}$ & 0.8741 & 0.9453 & 0.2884 \\
\hline
\end{tabular}

Notes: Figures in parentheses are standard errors for the regression coefficients. Significance levels of regression coefficients: $* 10 \%, * * 5 \%, * * * 1 \%$. The sample mean is subtracted from all levels variables except the non-English legal origin dummy variable so that the intercept can be interpreted as the time effect for a country with English legal origin, a sample-mean level of log income and emissions. See main text and Appendix for further information on variable definitions.

Table 2 presents the regression results for the three datasets. There are some commonalities in the drivers of emissions growth across the emissions sources and some differences. First, the average time effects (intercept terms) are negative and highly statistically significant for all three datasets. Industrial emissions declined at $0.96 \%$ p.a. in the absence of growth and average levels of the other effects in a country with English legal origin. As seemed likely from Figure 1c, non-industrial emissions declined more rapidly at $1.54 \%$ p.a. A bit surprisingly, the intercept for total emissions is even more negative $(-0.017)$ than that of either of the separate sources of emissions. 
The effect of GDP growth is highly statistically significant but the effect of growth is only about half as much for non-industrial emissions at the sample mean as for industrial emissions. The elasticity of industrial emissions with respect to growth at the sample mean is near to but statistically significantly lower than unity. The coefficient of the interaction term between the economic growth rate and the level of income is positive for all three regressions but is larger and statistically significant for industrial and total emissions but not for nonindustrial emissions. Therefore, there is no environmental Kuznets curve effect, not even for non-industrial emissions. On the other hand, the level of income has a negative effect on emissions growth, but this too is statistically significant only for industrial and total emissions.

The initial level of emissions intensity has a statistically significant negative effect for both industrial and non-industrial emissions, though a larger effect for industrial emissions. The size of the convergence effect is smaller than those found for industrial carbon dioxide and sulphur dioxide by Anjum et al. (2014).

Non-English legal origin has a positive effect but again this is not statistically significant for non-industrial emissions. The latter is surprising because property rights might be thought to be more important in the realm of deforestation than in limiting emissions of carbon dioxide from industry. Population density has a statistically significant negative effect on both industrial and non-industrial emissions, though the effect is greater in absolute value for nonindustrial emissions. This finding is surprising as usually we would assume that higher population density increases the rate of deforestation. But it seems that it reduces the rate of increase of this type of emissions. This is not because countries with high density already have few trees, as we control for the area of forest per capita in 1971. It is also not because non-industrial emissions were already high in 1971, as we control for emissions intensity too. Population density also has a negative effect on the growth rate of industrial emissions, which might be for the reasons we suggested in the previous section of the paper.

The coefficients of the remaining variables are very different for the different emissions sources. Summer temperature has a positive effect on the industrial emissions growth rate perhaps because of growing use of air conditioning in hot countries. But higher summer temperatures have a negative effect on non-industrial emissions. This can be explained as we control for winter temperatures. Tropical countries have high summer and winter temperatures. But the countries with the highest summer temperatures are mostly in the 
Middle East where there is little potential for non-industrial emissions as well as in the Sahel. Higher winter temperatures have a positive effect on non-industrial emissions growth, ceteris paribus. Countries with the highest winter temperatures are in the equatorial region, where deforestation potential is highest.

The resource endowment variables have relatively insignificant effects on emissions growth rates. A larger fossil fuel endowment increases the rate of growth of industrial emissions, as we would expect (Burke 2012, 2013; Stern, 2012). Freshwater endowments have statistically insignificant effects, though the effect on industrial emissions is positive. One explanation for this is that $\mathrm{SF}_{6}$ is the most potent known greenhouse gas and is emitted in aluminium and magnesium production. Iceland, which has the largest per capita freshwater resources also has one of the most rapid growth rates of industrial emissions because of the use of hydropower for aluminium smelting. This generates a spurious correlation between freshwater resources and the growth rate of industrial emissions. In fact, in an unweighted regression, freshwater resources have a highly statistically significant effect on industrial emissions growth for this reason. Per capita forest resources have a negative effect that is statistically significant at the $10 \%$ level on industrial emissions but surprisingly no effect on non-industrial emissions. Perhaps this reflects the trade-off between fossil fuel and biomass use.

Though the R-squared statistics cannot be exactly compared to each other, they do indicate that the model explains less of the growth in non-industrial emissions than in industrial emissions. The fit of the models for total and industrial emissions are very good when deviations are weighted for population size using the Buse R-squared.

\section{Discussion}

We find that there is a significant effect of economic growth on long-run growth in both industrial and non-industrial emissions. We find no support for the environmental Kuznets curve hypothesis. Instead, time and convergence effects and the effects of some specific control variables are significant. On the other hand, there is a reduction in emissions intensity with growth, particularly for non-industrial emissions. This rules out a simple IPAT style model too. Though we find that convergence is statistically significant, our analysis does not explain why emissions intensity is converging across countries. Convergence could be due to globalization leading to economic structures and the technologies used across countries 
becoming more similar over time or due to countries with high emissions intensities taking policy action to improve their environments and/or reduce their dependence on imported energy. Our results also show that though per capita emissions are declining over time in the absence of growth, using Tables 1 and 2 we see that the positive effect of growth in aggregate global income on industrial emissions is more than twice as large as the negative time effect. The picture for non-industrial emissions is more positive - the growth effect is smaller than the time effect. However, to this must be added the effect of growing population, which we assume has a 1 to 1 effect on emissions. As shown in the Appendix, the main regression results are similar when estimated using data from 1991-2010 instead of 1970-2010. Thus emissions are likely to continue to increase in the future unless stronger mitigation action is taken.

\section{References}

Angrist, J. D., and J.-S. Pischke. 2010. The credibility revolution in empirical economics: how better research design is taking the con out of econometrics. Journal of Economic Perspectives, 24(2): 3-30.

Anjum Z., P. J. Burke, R. Gerlagh, and D. I. Stern (2014) Modeling the emissions-income relationship using long-run growth rates, CCEP Working Papers 1403.

Barro, R. J. and X. Sala-i-Martin. 1992. Convergence. Journal of Political Economy 100(2): 223-51.

Bazzi, S., and M. A. Clemens. 2013. Blunt instruments: Avoiding common pitfalls in identifying the causes of economic growth. American Economic Journal: Macroeconomics 5(2): 152-86.

Blanco, G., R. Gerlagh, S. Suh, J. Barrett, H. de Coninck, C. F. Diaz Morejon, R. Mathur, N. Nakicenovic, A. O. Ahenkorah, J. Pan, H. Pathak, J. Rice, R. Richels, Steven J. Smith, David I. Stern, F. L. Toth, and P. Zhou. 2014. Drivers, trends and mitigation. In: O. Edenhofer et al., eds. Climate Change 2014: Mitigation of Climate Change. Contribution of Working Group III to the Fifth Assessment Report of the Intergovernmental Panel on Climate Change. Cambridge University Press, Cambridge, UK and New York, NY, USA.

Brännlund, R., A. Karimu, P. Söderholm (2014) Convergence in carbon dioxide emissions and the role of growth and institutions: A parametric and nonparametric analysis, CERE Working Paper 2014:12.

Brock, W. A. and M. S. Taylor. 2010. The green Solow model. Journal of Economic Growth 15: 127-53.

Burke, P. J. 2012. Climbing the electricity ladder generates carbon Kuznets curve downturns. Australian Journal of Agricultural and Resource Economics 56(2): 260-79.

Burke, P. J. 2013. The national-level energy ladder and its carbon implications. Environment and Development Economics 18(4): 484-503. 
Buse, A. 1973. Goodness of fit in generalized least squares estimation. American Statistician 27(3): 106-8.

Carson, R. T. 2010. The environmental Kuznets curve: Seeking empirical regularity and theoretical structure. Review of Environmental Economics and Policy 4(1): 3-23.

Ehrlich, P. R. and J. P. Holdren. 1971. Impact of population growth. Science 171(3977): 1212-7.

Feenstra, R. C., R. Inklaar, and M. P. Timmer. 2013. The next generation of the Penn World Table. NBER Working Papers 19255.

Herrerias, M. J. 2013. The environmental convergence hypothesis: Carbon dioxide emissions according to the source of energy. Energy Policy 61: 1140-50.

IPCC. 2014. Summary for policymakers. In: O. Edenhofer, R. Pichs-Madruga, Y. Sokona, E. Farahani, S. Kadner, K. Seyboth, A. Adler, I. Baum, S. Brunner, P. Eickemeier, B. Kriemann, J. Savolainen, S. Schlömer, C. von Stechow, T. Zwickel, and J.C. Minx (eds.) Climate Change 2014: Mitigation of Climate Change. Contribution of Working Group III to the Fifth Assessment Report of the Intergovernmental Panel on Climate Change. Cambridge University Press, Cambridge, UK and New York, NY, USA.

Jorgenson, A. K. 2014. Economic development and the carbon intensity of human wellbeing. Nature Climate Change 4(3): 186-9.

Jotzo, F., P. J. Burke, P. Wood, A. Macintosh, and D. I. Stern. 2012. Decomposing the 2010 global carbon dioxide emissions rebound. Nature Climate Change 2(4): 213-4.

Kaika, D., and E. Zerva. 2013a. The Environmental Kuznets Curve (EKC) theory-Part A: Concept, causes and the $\mathrm{CO}_{2}$ emissions case. Energy Policy 62: 1392-402.

Kaika, D., and E. Zerva. 2013b. The environmental Kuznets curve (EKC) theory. Part B: Critical issues. Energy Policy 62: 1403-11.

King, G. 1988. Statistical models for political science event counts: Bias in conventional procedures and evidence for the exponential Poisson regression model. American Journal of Political Science 32(3): 838-63.

La Porta, R., F. Lopez-de-Silanes, and A. Shleifer. 2008. The economic consequences of legal origins. Journal of Economic Literature 46(2): 285-332.

Maddala, G. S. 1977. Econometrics. McGraw-Hill, Singapore.

Mitchell, T. D., M. Hulme, and M. New. 2002. Climate data for political areas. Area 34: 10912 .

Norman, C. S. 2009. Rule of law and the resource curse: Abundance versus intensity. Environmental and Resource Economics 43: 183-207.

Pasten, R. and E. Figueroa. 2012. The environmental Kuznets curve: A survey of the theoretical literature. International Review of Environmental and Resource Economics 6: $195-224$ 
Petterson, F., D. Maddison, S. Acar, and P. Söderholm. 2014. Convergence of carbon dioxide emissions: A review of the literature. International Review of Environmental and Resource Economics 7: 141-78.

Raupach, M. R., G. Marland, P. Ciais, C. Le Quéré, J. G. Canadell, G. Klepper, and C. B. Field. 2007. Global and regional drivers of accelerating CO2 emissions. Proceedings of the National Academy of Sciences 104(24): 10288-93.

Romano, J. P. and M. Wolf. 2014. Resurrecting weighted least squares. University of Zurich, Department of Economics, Working Paper Series 172.

Steinberger, J. K., J. T. Roberts, G. P. Peters, and G. Baiocchi. 2012. Pathways of human development and carbon emissions embodied in trade. Nature Climate Change 2(2): 81-5.

Stern, D. I. 1994. Historical path-dependence of the urban population density gradient. Annals of Regional Science 28: 197-223.

Stern, D. I. 2004. The rise and fall of the environmental Kuznets curve. World Development 32(8): 1419-39.

Stern, D. I. 2005. Beyond the environmental Kuznets curve: Diffusion of sulfur-emissionsabating technology. Journal of Environment and Development 14(1): 101-24.

Stern, D. I. 2010. Between estimates of the emissions-income elasticity. Ecological Economics 69: 2173-82.

Stern, D. I. 2012. Modeling international trends in energy efficiency. Energy Economics 34: 2200-8.

Strazicich, M. C. and J. A. List. 2003. Are $\mathrm{CO}_{2}$ emission levels converging among industrial countries? Environmental and Resource Economics 24(3): 263-71.

Vollebergh, H. R. J., B. Melenberg, and E. Dijkgraaf. 2009. Identifying reduced-form relations with panel data: The case of pollution and income. Journal of Environmental Economics and Management 58(1): 27-42.

Wagner, M. 2008. The carbon Kuznets curve: A cloudy picture emitted by bad econometrics. Resource and Energy Economics 30: 388-408.

Wagner, M. in press. The environmental Kuznets curve, cointegration and nonlinearity. Journal of Applied Econometrics.

Westerlund, J., and S. A. Basher. 2008. Testing for convergence in carbon dioxide emissions using a century of panel data. Environmental and Resource Economics 40: 109-20.

York, R., E. A. Rosa, and T. Dietz. 2003. STIRPAT, IPAT and ImPACT: analytic tools for unpacking the driving forces of environmental impacts. Ecological Economics 46: 351-65. 


\section{Appendix}

\section{Data}

\section{Greenhouse Gas Emissions}

Data for greenhouse gas (GHG) emissions is sourced from the Emission Database for Global Atmospheric Research (EDGAR) version 4.2. This database provides information of calculated emissions for 232 countries and territories, and international transportation for years between 1970 and 2010. The data on emissions include direct GHGs, ozone precursor gases, acidifying gases, primary particulates, and stratospheric ozone depleting substances. This data can be freely downloaded from:

http://edgar.jrc.ec.europa.eu/overview.php?v=42FT2010

The 100 years global warming potential factors (GWP100) used for the GHGs included in the dataset are sourced from Forster et al. (2007), Oram et al. (2012), and Ivy et al. (2012) and are shown below. We used these to aggregate the various gases into carbon dioxide equivalent emissions. We aggregated the various sources of emissions into industrial emissions, covering sectors 1, 2, 3,6, and 7, (energy, industrial processes, product use, waste, and other anthropogenic sources) and non-industrial emissions covering sectors 4 and 5 (Agriculture and land-use change and forestry).

\section{$\underline{\mathrm{GHG}}$}

Carbon Dioxide $\left(\mathrm{CO}_{2}\right)$

Methane $\left(\mathrm{CH}_{4}\right)$

Nitrous oxide $\left(\mathrm{N}_{2} \mathrm{O}\right)$

Nitrogen trifluoride $\left(\mathrm{NF}_{3}\right)$

Sulphur hexafluoride $\left(\mathrm{SF}_{6}\right)$

Hydrofluorocarbons (HCFs):

HCF23

HCF32

HCF43

HCF125

HCF134

HCF143

HCF152

\section{GWP100 Factor}

1

25

298

17,200

22,800

14,800

675

1,640

3,500

1,430

4,470

124 
HCF227

HCF236

9,810

HCF245

1,030

HCF365

794

Perfluorocarbons (PCFs):

$\mathrm{C}_{2} \mathrm{~F}_{6}$

$\mathrm{C}_{3} \mathrm{~F}_{8}$

$\mathrm{C}_{4} \mathrm{~F}_{10}$

8,860

$\mathrm{C}_{5} \mathrm{~F}_{12}$

9,160

$\mathrm{C}_{6} \mathrm{~F}_{14}$

9,300

$\mathrm{C}_{7} \mathrm{~F}_{16}$

7,930

$\mathrm{cC}_{4} \mathrm{~F}_{8}$

10,300

$\mathrm{CF}_{4}$

GDP and Population

The GDP and population data are sourced from the Penn World Table (PWT) version 8.0 (Feenstra et al., 2013). PWT 8.0 provides GDP data adjusted for purchasing power parity for 167 countries between 1950-2011, though not all countries have a complete time series. For the period we are interested in, there are complete series for 143 countries. Following the advice of Feenstra et al. we compute the growth rates of GDP using the series RGDPNA, which uses the growth rate of real GDP from each country's national accounts to extrapolate GDP from 2005 to other years. RGDPNA is set equal to the variables CGDPO and RGDPO in 2005. The latter variables are output side measures of real GDP that take into account the effect of changes in the terms of trade in order to better represent the real production capacity of the economy.

Also following the recommendations of Feenstra et al., to measure the level of GDP we use the variable CGDPO, which is measured at constant 2005 millions of purchasing power parity adjusted dollars. This variable measures output-side GDP across countries using the reference price vector for each year and then adjusting for US inflation over time.

These data can be downloaded from www.ggdc.net/pwt. 


\section{Centrally Planned Economies}

We identify centrally planned economies using a dummy variable equal to one for those countries on the list of transition economies in Table 3.1 in IMF (2000). In our sample, these countries are: Albania, Bulgaria, Cambodia, China, Hungary, Laos, Poland, Romania, and Vietnam.

\section{Legal Origin}

We treat English legal origin as the default and assign zero-one dummies for German, French, and Scandinavian legal origin using the classification of La Porta et al. (2008). The data are available from:

http://scholar.harvard.edu/shleifer/publications/economic-consequences-legal-origins

\section{Temperature}

Average temperature in degrees Celsius for 1960-1990 by country and month are available from Mitchell et al. (2002). The data are available from:

http://www.cru.uea.ac.uk/ timm/climate/index.html

We average the temperature of the three summer months - June to August in the Northern Hemisphere and December to February in the Southern Hemisphere - to obtain a summer temperature variable. We average the temperature of the three winter months to obtain a winter temperature variable. This should give a better idea of the demand for cooling and heating than simply using the temperature of the hottest and coldest months.

\section{Resource Endowments}

We multiply Norman's (2009) ratio of the value of fossil fuel stocks to GDP in 1971 by GDP per capita at market exchange rates in 1971 (World Bank) to derive the value of per capita fossil fuel endowments in 1971. Data on per capita freshwater resources are from the World Development Indicators.

Forest cover data and land area in 1971 were sourced from Persson (1974) who estimated the area of different forest types for most countries in the world in 1973 or a close year preceding that. We summed the areas of various forest types as both closed and open forests and brushlands can provide biomass fuel and be subject to land clearing. 
As there are zero values for the level of these resources in many countries, we add one dollar to this value before taking logs. King (1988) noted that small changes in the constant used in this situation can drastically affect results. As the median value for countries with non-zero resources is $\$ 359$ this does not change the data for countries with significant resources by very much. We tested reducing this constant to 0.01 . This did not change the significance levels of the coefficients of the resource stock variables and did not change the values of the coefficients of the other variables in the model in any important way.

\section{Sample of Countries}

In total we found 129 countries that have data on all these variables. The list of countries is:

Albania, Angola, Antigua and Barbuda, Argentina, Australia, Austria, Bahamas, Bahrain, Bangladesh, Barbados, Belgium, Belize, Benin, Bhutan, Bolivia, Botswana, Brazil, Brunei Darussalam, Bulgaria, Burkina Faso, Burundi, Cambodia, Cameroon, Canada, Cape Verde, Central African Republic, Chad, Chile, China, Colombia, Comoros, Congo, Costa Rica, Cote d'Ivoire, Cyprus, Denmark, Djibouti, Dominican Republic, DR Congo, Ecuador, Egypt, El Salvador, Equatorial Guinea, Fiji, Finland, France, Gabon, Gambia, Ghana, Greece, Guatemala, Guinea, Guinea-Bissau, Honduras, Hungary, Iceland, India, Indonesia, Iran, Islamic Republic of, Iraq, Ireland, Israel, Italy, Jamaica, Japan, Jordan, Kenya, Korea, Kuwait, Laos, Lebanon, Liberia, Luxembourg, Madagascar, Malawi, Malaysia, Mali, Malta, Mauritania, Mauritius, Mexico, Mongolia, Morocco, Mozambique, Namibia, Nepal, Netherlands, New Zealand, Niger, Nigeria, Norway, Oman, Pakistan, Panama, Paraguay, Peru, Philippines, Poland, Portugal, Qatar, Romania, Rwanda, Saudi Arabia, Senegal, Sierra Leone, Singapore, South Africa, Spain, Sri Lanka, Sudan, Suriname, Swaziland, Sweden, Switzerland, Syria, Tanzania, Thailand, Togo, Trinidad and Tobago, Tunisia, Turkey, Uganda, United Kingdom, United States, Uruguay, Venezuela, Vietnam, Zambia, Zimbabwe.

\section{Uncertainties in the Data}

Blanco et al. (2014) discuss the uncertainty in emissions data. For $\mathrm{CO}_{2}$ emissions from fossil fuels and cement production the uncertainties are of the order of $\pm 8 \%$. Uncertainties for $\mathrm{CH}_{4}$ and the fluorinated gases are of the order of $\pm 20 \%$, while $\mathrm{N}_{2} \mathrm{O}$ and $\mathrm{CO}_{2}$ from land-use change are of the order of $\pm 60 \%$ and 50-75\%, respectively. The uncertainties in global land-use change emissions are sufficiently high to make both the direction and magnitude of trends over recent decades uncertain. 


\section{Results for 1991-2010}

We repeated the analysis in the paper for the period 1991 to 2010 to see whether there were substantial changes in the drivers of GHG emissions over the period. Data on forest cover in 1990 are taken from the World Development Indicators. The main results are very robust to this change of time period; however, the effects of some of the control variables do change.

\section{Regression Results: 1991-2010}

\begin{tabular}{|l|l|l|l|}
\hline Data set & Total & $\begin{array}{l}\text { Industrial } \\
\text { Emissions }\end{array}$ & $\begin{array}{l}\text { Non-Industrial } \\
\text { Emissions }\end{array}$ \\
\hline Emissions & $-0.0146^{* * *}$ & $-0.0098^{* * *}$ & $-0.0162^{* * *}$ \\
& $(0.0021)$ & $(0.0015)$ & $(0.0026)$ \\
\hline$\hat{G}_{i}$ & $0.7241^{* * *}$ & $0.7990^{* * *}$ & $0.3962^{* * *}$ \\
& $(0.0605)$ & $(0.0418)$ & $(0.0823)$ \\
\hline$G_{i}$ & -0.0044 & $-0.0032^{*}$ & -0.0029 \\
& $(0.0035)$ & $(0.0017)$ & $(0.0023$ \\
\hline$G_{i} \hat{G}_{i}$ & $0.2178^{* *}$ & $0.0984^{*}$ & 0.0930 \\
\hline$E_{i 0}-G_{i 0}$ & $(0.0867)$ & $(0.0515)$ & $(0.0703)$ \\
\hline Non-English Legal Origin & $-0.0092^{* * *}$ & $-0.0128^{* * *}$ & $-0.0048^{* *}$ \\
& $(0.0032)$ & $(0.0028)$ & $(0.0024)$ \\
\hline Summer Temperature & -0.0004 & $0.0044^{* *}$ & -0.0025 \\
& $(0.0028)$ & $(0.0019)$ & $(0.0030)$ \\
\hline Winter Temperature & $0.0020^{* * *}$ & $0.0016^{* * *}$ & 0.0006 \\
& $(0.0006)$ & $(0.0004)$ & $(0.0006)$ \\
\hline Log Fossil Fuel per Capita 1971 & $-0.0005^{*}$ & -0.0001 & -0.0000 \\
& $(0.0003)$ & $(0.0002)$ & $(0.0003)$ \\
\hline Log Freshwater per Capita 1992 & $-0.0014^{* *}$ & 0.0000 & $-0.0021^{* * *}$ \\
& $(0.0007)$ & $(0.0004)$ & $(0.0008)$ \\
\hline Log Forest per Capita 1990 & $0.0033^{*}$ & $0.0035^{* * *}$ & 0.0012 \\
& $(0.0018)$ & $(0.0013)$ & $(0.0024)$ \\
\hline Log Population Density & -0.0042 & $-0.0035^{* * *}$ & -0.0036 \\
& $(0.0026)$ & $(0.0016)$ & $(0.0036)$ \\
\hline $\bar{R}_{\text {Buse }}^{2}$ & $-0.0025^{* *}$ & $-0.0019^{* * *}$ & $-0.0060^{* * *}$ \\
\hline & $(0.0010)$ & $(0.0007)$ & $(0.0016)$ \\
\hline & 0.8282 & 0.9087 & 0.3694 \\
\hline
\end{tabular}

Notes: Figures in parentheses are standard errors for the regression coefficients. Significance levels of regression coefficients: $* 10 \%, * * 5 \%, * * * 1 \%$. The sample mean is subtracted from all levels variables except the non-English legal origin dummy variable so that the intercept can be interpreted as the time effect for a country with English legal origin, a sample-mean level of log income and emissions. See main text and Appendix for further information on variable definitions.

\section{References}

Forster, P., V. Ramaswamy, P. Artaxo, T. Berntsen, R. Betts, D.W. Fahey, J. Haywood, J. Lean, D.C. Lowe, G. Myhre, J. Nganga, R. Prinn, G. Raga, M. Schulz, and R. Van Dorland. 2007. Changes in atmospheric constituents and in radiative forcing. In: S. Solomon, D. Qin, M. Manning, Z. Chen, M. Marquis, K. B. Averyt, M. Tignor, and H. L. Miller (eds.), Climate Change 2007: The Physical Science Basis. Contribution of Working Group I to the Fourth 
Assessment Report of the Intergovernmental Panel on Climate Change. Cambridge, United Kingdom and New York, NY, USA: Cambridge University Press.

Ivy, D. J., M. Rigby, M. Baasandorj, J. B. Burkholder, and R. G. Prinn. 2012. Global emission estimates and radiative impact of C4F10, C5F12, C6F14, C7F16 and C8F18. Atmospheric Chemistry and Physics 12: 7635-45.

Oram, D. E., F. S. Mani, J. C. Laube, M. J. Newland, C. E. Reeves, W. T. Sturges, S. A. Penkett, C. A. M. Brenninkmeijer, T. Rockmann, and P. J. Fraser. 2012. Long-term

tropospheric trend of octafluorocyclobutane. Atmospheric Chemistry and Physics 12: 261-69.

Persson, R. (1974) World Forest Resources: Review of the World's Forest Resources in the Early 1970's. Department of Forest Survey, Royal College of Forestry, Stockholm. Research Notes 17. 